\title{
Hot Deformation and Recrystallization of 3\% Silicon Steel Part 2: Effect of Microstructural Variables on Static Recrystallization
}

\author{
S. AKTA, G. J. RICHARDSON ${ }^{11}$ and C. M. SELLARS ${ }^{21}$ \\ Faculty of Mechanical Engineering, University of Aleppo, Syria. \\ 1) School of Engineering, Sheffield Hallam University,
} UK. 2) Department of Engineering Materials, The University of Sheffield, UK.

(Received on March 22, 2005; accepted on August 4, 2005)

\begin{abstract}
The recrystallization kinetics and the recrystallized grain size of $3 \%$ Si steel after hot rolling at temperatures of 900 to $1100^{\circ} \mathrm{C}$ and annealing at the rolling temperature have been investigated for a range of initial grain sizes from 140 to $850 \mu \mathrm{m}$ and initial austenite contents from 0 to $16 \%$. It is shown that, in single phase ferrite, nucleation of recrystallization takes place only at grain boundaries, whereas some intragranular nucleation also occurs when austenite is present during rolling. Finer initial grain size and the presence of austenite therefore lead to faster recrystallization and to finer recrystallized grain size.

Recovery during annealing causes a rapid decrease in stored energy, and therefore a decrease in the growth rate of recrystallizing regions with annealing time. This results in plateaux in the fraction recrystallized, which decrease in level with increase in initial grain size and with decrease in initial austenite content. Recrystallization kinetics approximate closely to site saturated nucleation and to negligible coarsening of recrystallized grains, leading to simple relationships between the time for 0.3 fraction of recrystallization and the fully recrystallized grain size.
\end{abstract}

KEY WORDS: silicon steel; hot rolling; static recrystallization; quantitative metallography; grain size; austenite content.

\section{Introduction}

Silicon steels are industrially important because of their electrical properties, which may be developed to be orientation dependent or non-orientation dependent by appropriate thermomechanical processing. The steels are also of interest to the physical metallurgist, because a $3 \%$ Si steel with low carbon content $(\leq 0.02 \% \mathrm{C})$ remains ferritic over the whole temperature range to the solidus, whereas higher carbon contents result in partial transformation to austenite in the hot working temperature range. It has been shown ${ }^{1)}$ that grain sizes in the range 180 to $850 \mu \mathrm{m}$ have no effect on the stress-strain curves under hot working conditions and that the presence of up to $16 \%$ austenite has only a small effect that can be described by a law of mixtures from the flow stresses of ferrite and austenite. However, both grain size and austenite content present during deformation have major effects on the static recrystallization behaviour after hot deformation.

The present paper reports the results of quantitative metallographic measurements of the effects of initial grain size and austenite content during hot rolling on the kinetics of static recrystallization and on the recrystallized grain size. The observations are interpreted in terms of a physically based model derived from transmission electron metallographic studies of hot worked aluminium alloys, which also undergo only work hardening and dynamic recovery during hot deformation. ${ }^{2-8)}$

\section{Experimental Procedure}

The full chemical compositions of the steels investigated and the overall experimental procedure have been reported previously, ${ }^{1)}$ but the essential features relevant to the present study of the effects of grain size and austenite, $\gamma$, content are summarised here. Most results were obtained on a commercial steel of initial composition $3.16 \% \mathrm{Si}, 0.036 \%$ C (Mat(A)), for which different initial grain sizes and austenite contents were produced by preliminary thermomechanical processing.

In the as-received hot rolled condition, Mat(A) had a nearly equiaxed grain size of $850 \pm 50 \mu \mathrm{m}$ and, after reheating for $60 \mathrm{~min}$ in an exothermic gas atmosphere for experimental rolling, had austenite volume fractions of $16 \%$ at $1100^{\circ} \mathrm{C}, 12 \%$ at $1000^{\circ} \mathrm{C}$ and $5 \%$ at $900^{\circ} \mathrm{C}$. Comparison of these values with published data ${ }^{1)}$ indicated that equilibrium had probably been attained, giving about $0.02 \% \mathrm{C}$ in solution in the ferrite over the experimental temperature range. Annealing in the exothermic gas produced progressive decarburization and hence a gradient in volume fraction of austenite. The $60 \mathrm{~min}(3600 \mathrm{~s})$ reheat for rolling at $1100^{\circ} \mathrm{C}$ reduced the austenite content near the surface of the $30 \mathrm{~mm}$ thick slabs, but it was still uniform at $16 \% \gamma$ from 1/4 thickness to the centre. More extended reheating was used to reduce the austenite content to $9.5,5.5$ and eventually $0 \%$ at $1 / 4$ thickness, while retaining the grain size of $850 \mu \mathrm{m}$ (Mat(A2)), to investigate the influence of austenite on the recrystallization behaviour during anneal- 
ing after hot rolling.

Other slabs of Mat(A) were rolled and annealed to produce different grain sizes of 140, 235 (Mat(A1)), and $475 \mu \mathrm{m}$ with $16 \%$ austenite present, and of 180 (Mat(A3)), 340 and $580 \mu \mathrm{m}$ with $0 \%$ austenite present, for further rolling and annealing to investigate the influence of grain size on recrystallization behaviour. It is noteworthy that while there is any austenite present at a particular position in the slab used for metallographic investigation (1/4 thickness and the centre), the carbon content in solution is expected to remain at about $0.02 \% \mathrm{C}$, whereas once single phase ferrite is produced, further annealing reduces the carbon in solution to very low levels. For comparison of results with decarburized Mat(A), a second steel Mat(B) of composition $3.31 \% \mathrm{Si}, 0.016 \% \mathrm{C}$ was produced. This had a grain size of $233 \pm 10 \mu \mathrm{m}$ and remained single phase ferrite at all reheating temperatures. ${ }^{1)}$

Experimental rolling was carried out on a $50 \mathrm{t}$ Hille rolling mill. For most of the investigation in this paper, a total equivalent strain of 0.82 was applied in two sequential passes of $30 \%$ reduction. A chromel-alumel thermocouple embedded to the centre of the slab was used to record temperature during rolling, which included $10 \mathrm{~s}$ from withdrawal of the slab from the furnace to the first pass and about $15 \mathrm{~s}$ between passes. Rolling temperatures quoted are slab centre temperatures at entry to the first pass. As discussed elsewhere, ${ }^{9)}$ there was no detectable recrystallization in the coarse grained materials rolled by a single pass of $30 \%$ reduction on annealing for at least an order of magnitude longer time that the $15 \mathrm{~s}$ interpass time, even at $1100^{\circ} \mathrm{C}$. For the smallest grain sizes, recrystallization may have started in the interpass time. The effect of recovery and recrystallization between pass 1 and pass 2 on the recrystallization behaviour after pass 2 is discussed elsewhere. ${ }^{10)}$

All slabs in this investigation were water quenched within about $2 \mathrm{~s}$ of exit from the rolls. Small specimens were then cut, and annealed in the same exothermic gas atmosphere used for reheating. All annealing times reported in this paper are equivalent isothermal times. ${ }^{1)}$ Specimens were quenched after annealing, sectioned on the throughthickness/longitudinal plane, mechanically polished and electrolytically etched in Morris' reagent. ${ }^{1)}$ Microstructures were examined optically and the fraction recrystallized was determined by point counting using a grid attached to the screen of the projection microscope and traverses close to $1 / 4$ slab thickness and/or close to the centre-line. Recrystallized grains were nearly equiaxed, so grain sizes were measured as linear intercepts along the same traverses. In specimens without microstructural gradients before rolling, they were also measured on perpendicular traverses. Sufficient points or boundaries were counted to give less than $5 \%$ relative error in the measured values of volume fraction recrystallized and grain size. In a few cases, the migrating boundary area separating recrystallized from unrecrystallized regions was also measured in order to obtain growth rates using the Cahn-Hagel ${ }^{11)}$ equation. Because the unrecrystallized regions are heavily elongated, the number of boundaries per unit length must be measured in both the longitudinal and through-thickness directions. ${ }^{12,13)}$ In order to have sufficient boundaries to measure, these measurements could only be made on the fine grained materials of uniform initial microstructures.

\section{Results}

Typical microstructures observed after deformation and after annealing have been illustrated earlier ${ }^{1)}$, and additional examples are given in Fig. 1. Figure 1(a) shows the structure of a single phase alloy in which nucleation of recrystallization is seen to take place exclusively at grain boundaries, with triple points being particularly favoured sites. When particles of austenite are present, these occur mainly at the ferrite grain boundaries, and enhance nucleation of recrystallization along the boundaries, without triple points appearing to be favoured, Fig. 1(b), and Fig. 6 in the earlier paper. ${ }^{1)}$ However, occasionally nucleation of recrystallization is observed at austenite particles, which appear to be within ferrite grains, Fig. 1(c). The role of grain boundaries and of austenite particles is similar over the whole temperature range of observation Fig. 1(d). It is also apparent from Fig. 1 that the subgrain structure in deformed grains is revealed by the etching procedure. The subgrains are clearly resolved from relatively low strains, particularly after deformation at $1100^{\circ} \mathrm{C}$ and their linear intercept size is shown as a function of strain in Fig. 2. The single phase and two phase alloys both show subgrain sizes decreasing continuously with strain from about $20 \mu \mathrm{m}$ at strain of 0.2 to about $7 \mu \mathrm{m}$ at a strain of 1.2 .

Recrystallization curves for the materials with grain sizes less than about $250 \mu \mathrm{m}$, shown previously, ${ }^{1)}$ and illustrated in Fig. 3 all have the characteristic sigmoidal form. Figure 3 shows that the presence of $16 \% \gamma$ during deformation accelerates recrystallization. This accelerating effect is more pronounced in material of coarse, $850 \mu \mathrm{m}$, initial grain size, Fig. 4. It is also clear from this figure that recrystallization does not go to completion in this coarse grained material, but terminates at a plateau level, $X_{\mathrm{p}}$, which decreases with decrease in the amount of austenite present during deformation. The overall effect of austenite on recrystallization kinetics is summarised in Fig. 5, which shows the time to 0.3 fraction of recrystallization, $t_{0.3}$, and in Fig. 6, which shows the level of the plateau $X_{\mathrm{p}}$, for the coarse grained material. For the present work, $t_{0.3}$, rather than the more usual $t_{0.5}$, has been used to characterise recrystallization kinetics in order to minimise the influence of the presence of a plateau. Recrystallization curves for materials of different initial grain size with $16 \%$ austenite present during rolling and with no austenite present are shown in Fig. 7. The measurements made at the centre-line and at $1 / 4$ thickness of the slabs all showed similar trends, with somewhat faster kinetics and a higher plateau level at 1/4 thickness, ${ }^{1)}$ so only the mean values are shown in Fig. 7. The overall effects of original grain size on recrystallization kinetics are summarised in Fig. 8, which shows the time to 0.3 fraction of recrystallization, $t_{0.3}$, and in Fig. 9, which shows the level of plateau, for materials with $16 \%$ and $0 \%$ austenite present during rolling.

The presence of austenite particles during rolling, and the original grain size also influence the final recrystallized grain size, as shown in Figs. 10 and 11, respectively. It is clear from Fig. 10 that the presence of austenite during rolling significantly reduces the recrystallized grain size. 

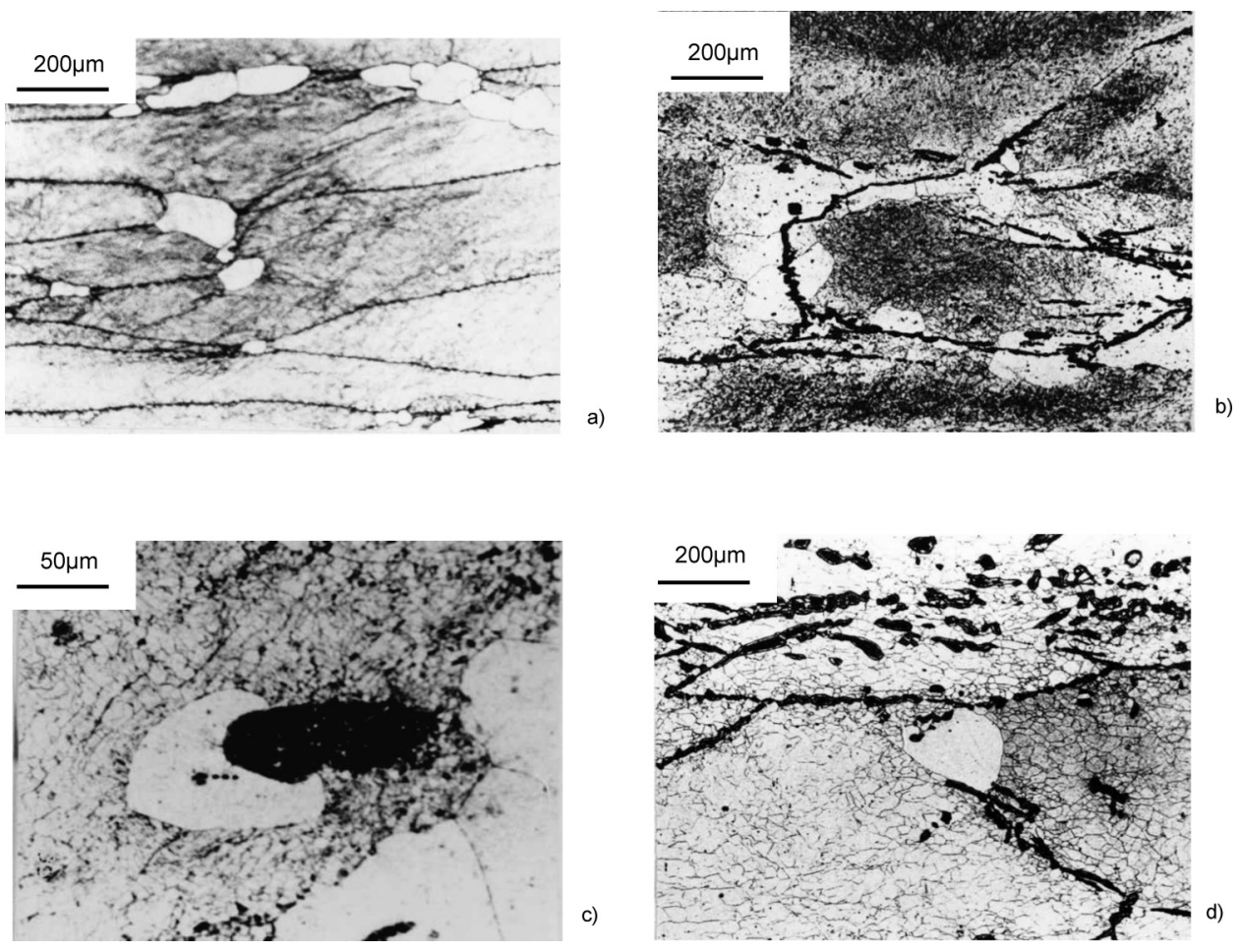

Fig. 1. Optical micrographs showing the early stages of static recrystallization: (a) single phase material (Mat(A3)) of grain size $180 \mu \mathrm{m}$ deformed to a strain of 0.59 at $900^{\circ} \mathrm{C}$ and annealed for $8 \mathrm{~s}$ at $900^{\circ} \mathrm{C}$, (b), (c) two phase material (Mat(A)) of grain size $850 \mu \mathrm{m}$ with $5 \% \gamma$, deformed to a strain of 0.82 at $900^{\circ} \mathrm{C}$ annealed for $370 \mathrm{~s}$ at $900^{\circ} \mathrm{C}$, (d) two phase material $(\operatorname{Mat}(\mathrm{A}))$ of grain size $850 \mu \mathrm{m}$ with $16 \% \gamma$ deformed to a strain of 0.82 at $1100^{\circ} \mathrm{C}$ and quenched in $2 \mathrm{~s}$.

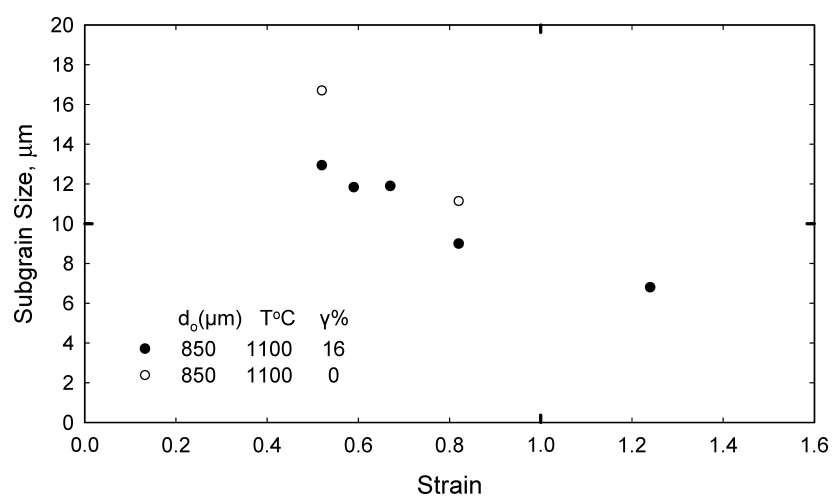

Fig. 2. Dependence of the size of subgrains observed in optical micrographs on strain in coarse grained single and two phase materials (Mat(A2) and (A)) deformed at $1100^{\circ} \mathrm{C}$.

Also, Fig. 11, the presence of austenite decreases the dependence of recrystallized grain size on the original grain size.

In a few cases the size of grains in the recrystallized areas, $d_{\mathrm{r}}$, was measured as a function of annealing time to give the results illustrated in Fig. 12. For the smaller grain sized material, the recrystallizing grain size increased continuously with time as recrystallization progressed to completion, whereas for the coarse grained material, in which a plateau of recrystallization was reached at about $100 \mathrm{~s}$, Fig. 7 , the grain size also reached a plateau value at the same time.

For a few conditions with small original grain size, when recrystallization went to completion, the migrating boundary area per unit volume, $S_{\mathrm{v}}^{\mathrm{mig}}$, was measured as a function of annealing time. Results illustrating the effects of austen-
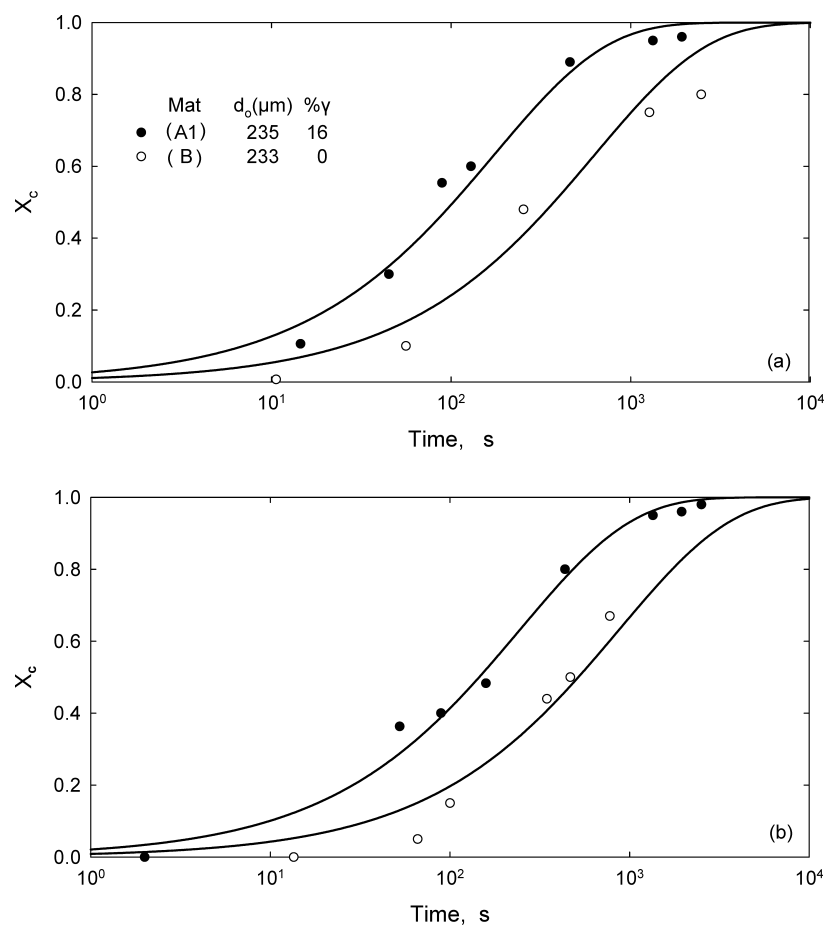

Fig. 3. Isothermal recrystallization curves measured at the centre of slabs of Mat(A1) and (B) annealed at $900^{\circ} \mathrm{C}$ after rolling to a strain of 0.82 at (a) $900^{\circ} \mathrm{C}$ and (b) $1100^{\circ} \mathrm{C}$.

ite present during rolling and of rolling strain are shown as a function of fraction recrystallized in Fig. 13. It is apparent that the maximum value of $S_{\mathrm{v}}^{\mathrm{mig}}$ increases systematically with conditions that lead to smaller recrystallised grain sizes. From these results the growth rate, $G$, was determined from the Cahn-Hagel equation ${ }^{11)}$ 

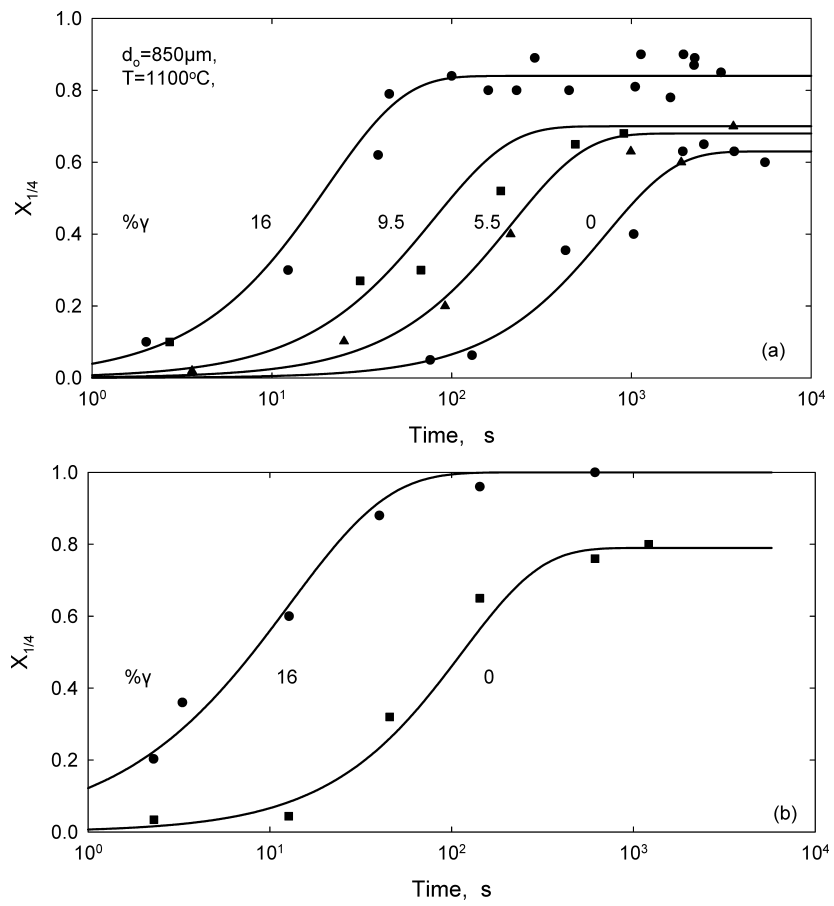

Fig. 4. Isothermal recrystallization curves measured at quarter thickness of slabs of different austenite content annealed at $1100^{\circ} \mathrm{C}$ after rolling at $1100^{\circ} \mathrm{C}$ to strains of (a) 0.82 and (b) 1.24 .

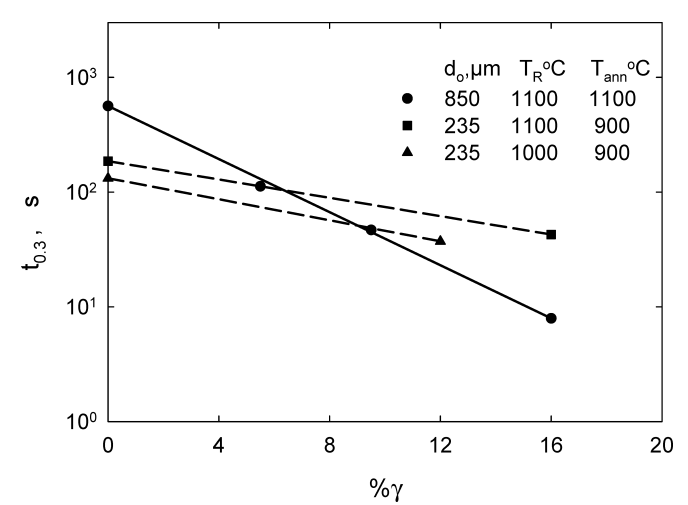

Fig. 5. Effect of percentage of austenite present during rolling to a strain of 0.82 at temperatures of $1100^{\circ} \mathrm{C}$ and $1000^{\circ} \mathrm{C}$ on the time for 0.3 fraction of recrystallization at the centre of coarse and finer grained slabs.

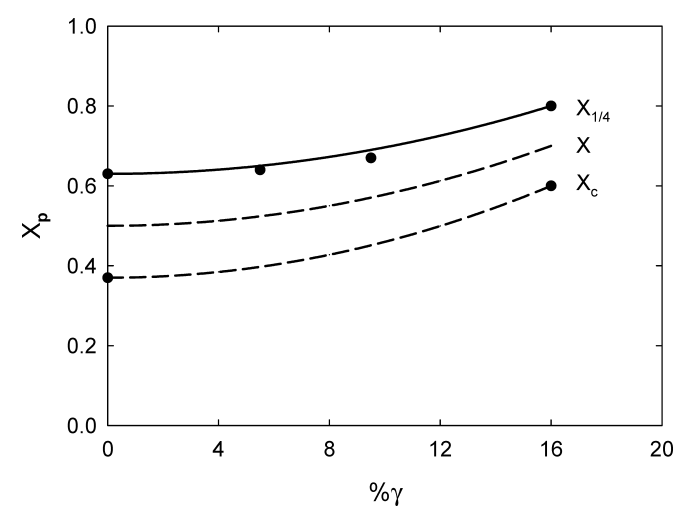

Fig. 6. Effect of percentage of austenite present during rolling to a strain of 0.82 at $1100^{\circ} \mathrm{C}$ on the fraction of recrystallization at the plateau measured at the centre, $X_{\mathrm{c}}$, and at a quarter thickness $X_{1 / 4}$, of slabs of coarse grained material.
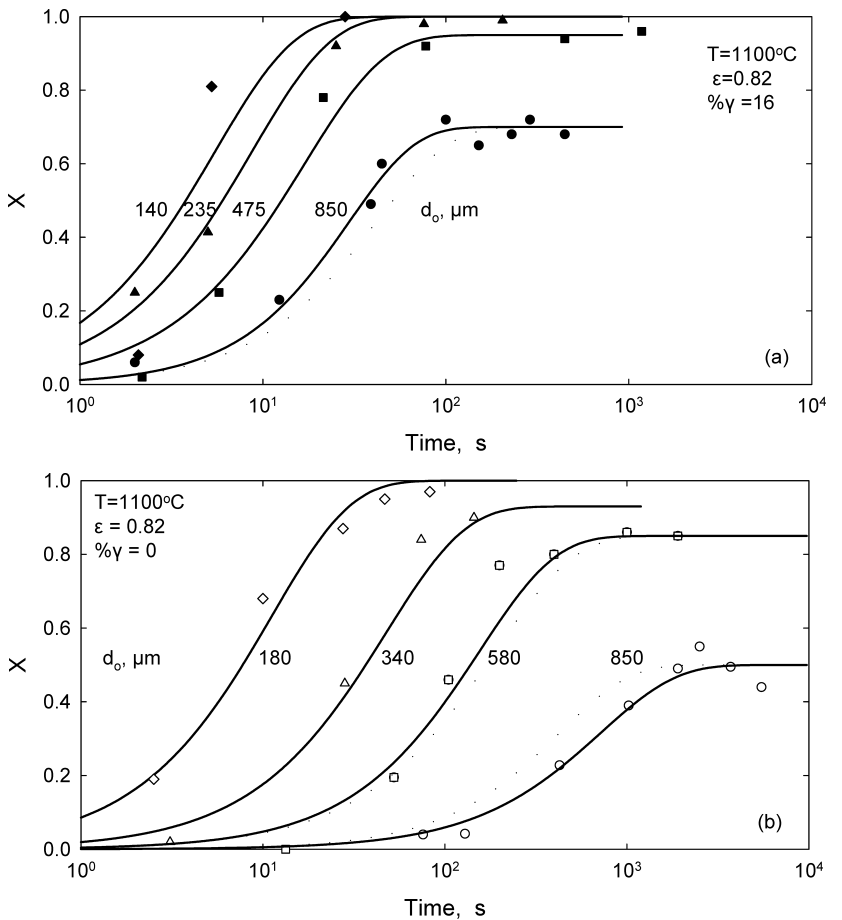

Fig. 7. Isothermal recrystallization curves, average of measurements at the centre and a quarter thickness, of slabs of different initial grain size annealed at $1100^{\circ} \mathrm{C}$ after rolling at $1100^{\circ} \mathrm{C}$ to a strain of 0.82 , (a) containing $16 \%$ austenite and (b) single phase ferrite.

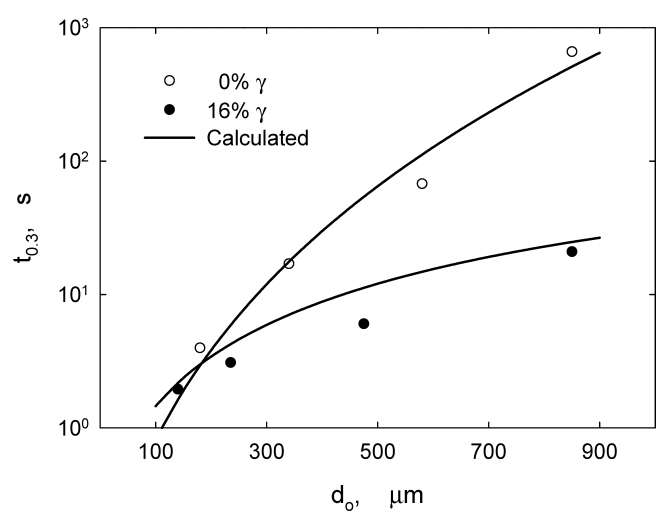

Fig. 8. Effect of initial grain size on the time for 0.3 fraction of recrystallization during annealing at $1100^{\circ} \mathrm{C}$ after rolling to a strain of 0.82 at $1100^{\circ} \mathrm{C}$ with 0 and $16 \%$ and austenite present during rolling. (Lines calculated from Eqs. (6) and (13) with values of the constants from Table 1 and Fig. 18.)

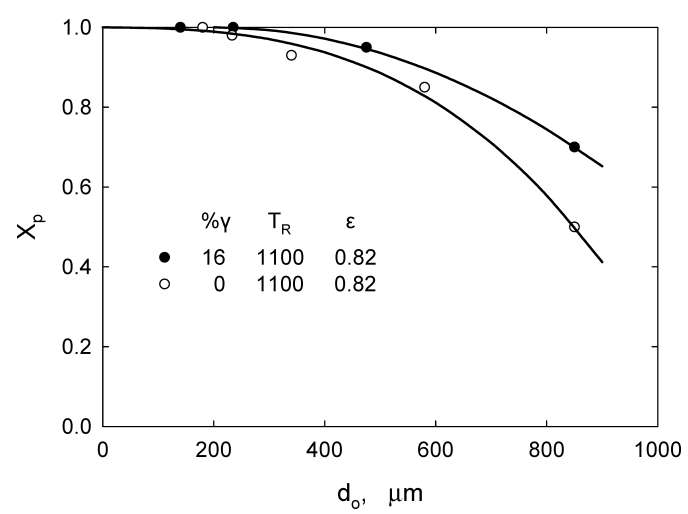

Fig. 9. Effect of initial grain size during rolling to a strain of 0.82 at $1100^{\circ} \mathrm{C}$ on the mean fraction of recrystallization at the plateau for material with 0 and $16 \%$ austenite present during rolling. 


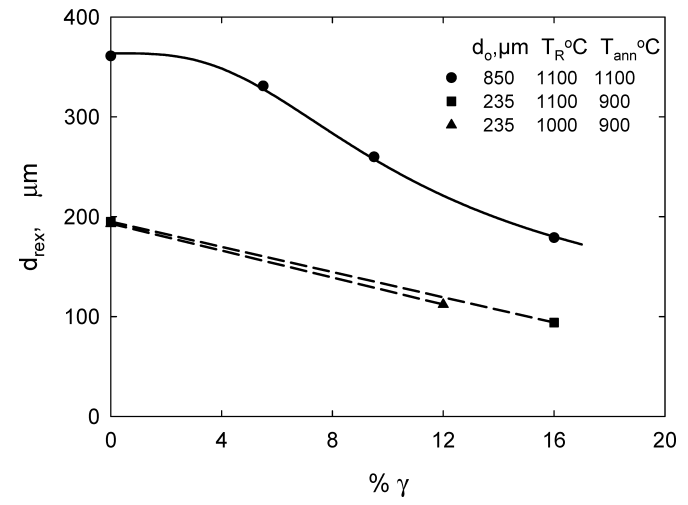

Fig. 10. Dependence of the recrystallized grain size at the centre of slabs on austenite content present during rolling to a strain of 0.82 at $1100^{\circ} \mathrm{C}$ and $1000^{\circ} \mathrm{C}$.

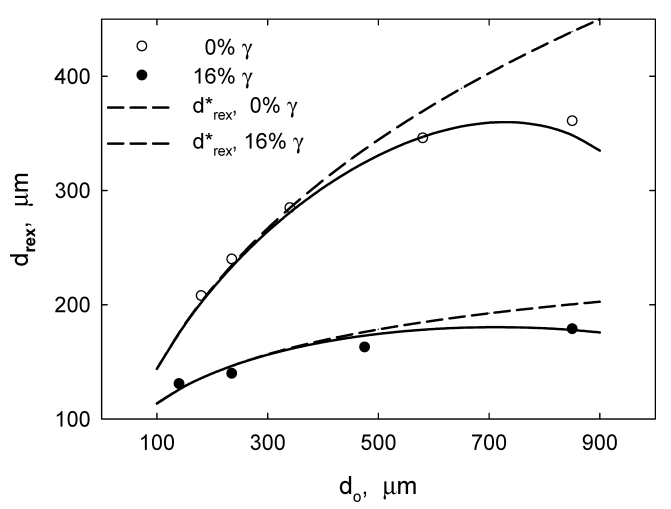

Fig. 11. Dependence of recrystallized grain size on the original grain size in materials containing 0 and $16 \%$ austenite during rolling to a strain of 0.82 at $1100^{\circ} \mathrm{C}$ and annealing at $1100^{\circ} \mathrm{C}$. (Lines calculated from Eqs. (4) and (6) with values of constants from Fig. 9 and Table 1.)

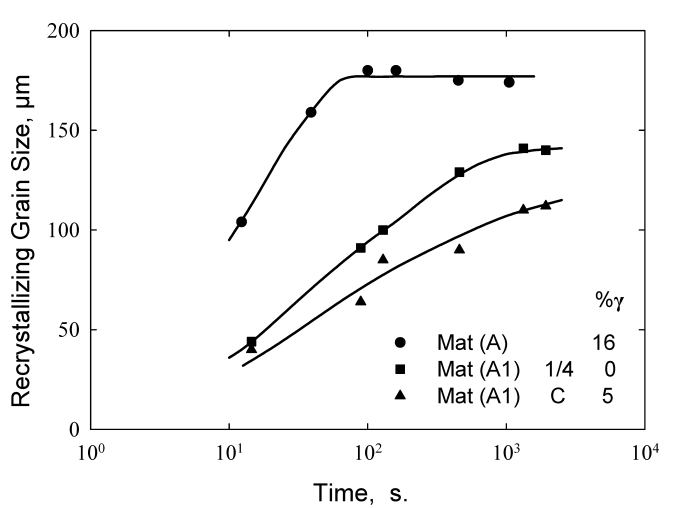

Fig. 12. Grain size in recrystallized areas as a function of time of annealing after rolling to a strain of 0.82 in Mat(A), $\left(d_{0}=850 \mu \mathrm{m}, 16 \% \gamma\right.$, rolled $1100^{\circ} \mathrm{C}$ and annealed $\left.1100^{\circ} \mathrm{C}\right)$ and $\operatorname{Mat}(\mathrm{A} 1),\left(d_{0}=235 \mu \mathrm{m}, 0 \% \gamma\right.$ at $1 / 4$ thickness and $5 \% \gamma$ at the centre of slabs rolled $900^{\circ} \mathrm{C}$ and annealed $900^{\circ} \mathrm{C}$ ).

$$
G=\frac{1}{S_{\mathrm{v}}^{\operatorname{mig}}} \frac{d X}{d t}
$$

where $d X / d t$ is the recrystallization rate at a given time. This was determined by drawing tangents to the appropriate recrystallization curves, Fig. 3(a) in this paper and Fig. 1 in reference $^{9)}$ at the times, $t$, when $S_{\mathrm{v}}^{\text {mig }}$ was measured. These tangents give

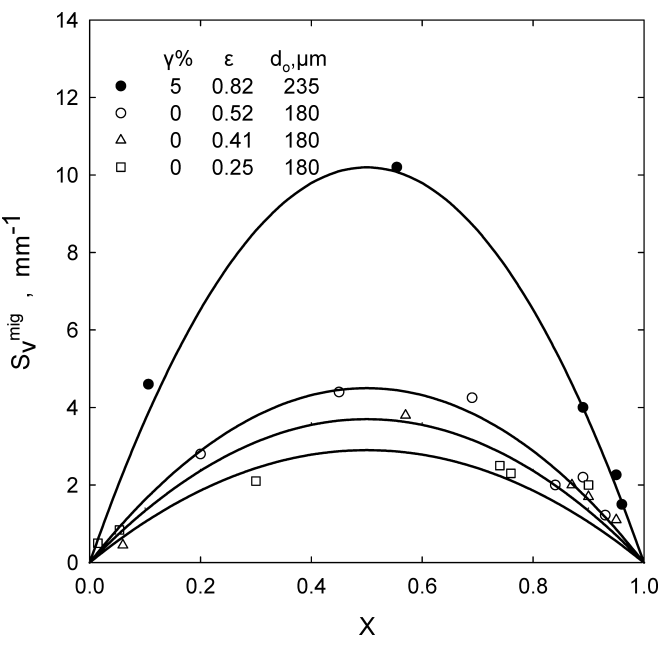

Fig. 13. Dependence of migrating boundary area per unit volume on fraction recrystallized after rolling to various strains at $900^{\circ} \mathrm{C}$ and annealing at $900^{\circ} \mathrm{C}$.

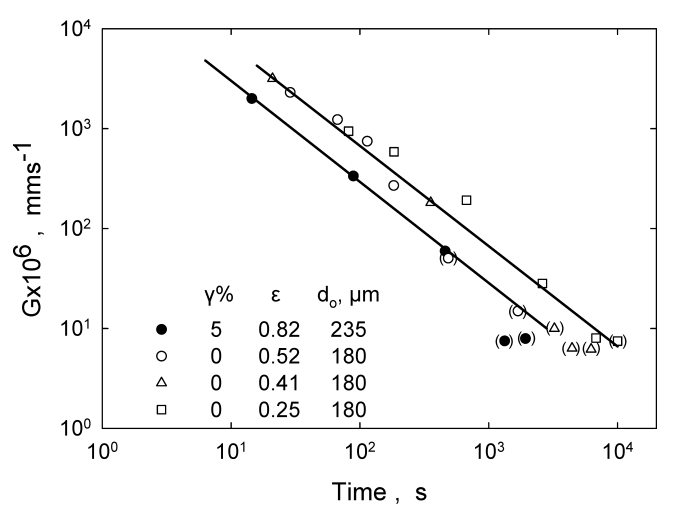

Fig. 14. Dependence of growth rate on time of annealing at $900^{\circ} \mathrm{C}$ after rolling to various strains at $900^{\circ} \mathrm{C}$.

$$
\frac{d X}{d \log t}=2.3 t \frac{d X}{d t}
$$

The resulting values of $G$ are shown as a function of annealing time in Fig. 14, where the data points in brackets arise from times leading to fractions recrystallized, $X \geq 0.9$. The accuracy of $G$ in this region is poor, partly because of the few migrating boundaries for measurement, but mainly because of large uncertainties in the slopes of the recrystallization curves. For a strain of 0.25 , all the data fall close to a line of slope -1 , but for the higher strains there appear to be systematic deviations at longer times, indicating that $G$ falls more rapidly than expected from the power law. It is noteworthy that the growth rates fall by more than two orders of magnitude during recrystallization, indicating a major effect of recovery, and possibly a decrease in boundary mobility with time. Also, the presence of $5 \%$ austenite leads to a systematic reduction in growth rate by a factor of about 2.5.

\section{Discussion}

The observation of well developed substructure in the deformed grains, Fig. 1, facilitates distinguishing deformed grains from recrystallized grains, but the apparent subgrain sizes measured from the optical micrographs, Fig. 2, are large. Even after high strains at $1100^{\circ} \mathrm{C}$ the apparent sub- 
grain size of about $7 \mu \mathrm{m}$ is twice as large as the subgrain size measured by transmission electron microscopy in IF steel deformed in the ferrite range at a flow stress of $40 \mathrm{MPa},{ }^{14)}$ which is the same as the flow stress of the $3 \%$ silicon steel at $1100^{\circ} \mathrm{C}$. ${ }^{1)}$ A discrepancy between optical subgrain sizes and the sizes measured by electron microscopy has long been established ${ }^{15)}$ and indicates that only subgrain boundaries with misorientations above some critical value are observable optically. This would lead to the apparent decrease in subgrain size with increase in strain above 0.2, Fig. 2, even though the steady state flow stress is attained by a strain of $0.2,{ }^{1)}$ because mean misorientation is expected to continue to increase with strain. ${ }^{7,14}$ ) A critical misorientation for etching is also consistent with the apparent disappearance of substructure in coarse deformed grains by recovery during annealing for long times, when there is a plateau in the recrystallization curves. Reduction in subgrain boundary misorientation and annihilation of dislocations and subgrain boundaries by recovery are expected at long times of annealing.

\subsection{Nucleation of Recrystallization}

From the qualitative observations, it is apparent that grain boundaries are the dominant sites for nucleation of recrystallized grains, even when particles of austenite are present during deformation. These particles are inhomogeneously distributed, with the majority sited at grain boundaries, ${ }^{1)}$ but with significant numbers inside some grains, Fig 1. Figure 12 shows that, once nucleated, the mean size of the recystallizing grains increases continuously in the smaller grain size material until recrystallization is complete, whereas in the coarse grained material, when the plateau in recrystallization is reached, the grain size remains constant. This indicates that, even at $1100^{\circ} \mathrm{C}$, grain coarsening in the recrystallized regions is negligible.

In Fig. 15, the size of recrystallizing grains is plotted against the fraction recrystallized, measured on the same specimens, (shown for Mat(A) as the curve for $850 \mu \mathrm{m}$ initial grain size in Fig. 7, and for Mat(A1) in the earlier paper, ${ }^{1)}$ Fig. 17). The lines in this figure are drawn according to the relationship.

$$
d_{\mathrm{r}}=X^{1 / 3} d_{\mathrm{rex}}^{*}
$$

where $d_{\mathrm{r}}$ is the size of recrystallizing grains at fraction $X$ of recrystallization, and $d_{\mathrm{rex}}^{*}$ is the fully recrystallized grain size. In the absence of grain coarsening, this equation is expected to apply when nucleation is site saturated. ${ }^{12)}$ It can be seen that the data points are all reasonably fitted by Eq. (3), indicating that nucleation is complete during the very early stages of recrystallization.

In order to interpret the measured final recrystallized grain sizes, $d_{\text {rex }}$, when there was a plateau in the recrystallization curve, Eq. (3) was applied to calculate the value expected, $d_{\text {rex }}^{*}$, if recrystallization had continued to completion as

$$
d_{\mathrm{rex}}^{*}=d_{\mathrm{rex}} X_{\mathrm{p}}^{-1 / 3}
$$

where $X_{\mathrm{p}}$ is the fraction recrystallised at the plateau. The broken part of the curve for Mat(A) in Fig. 15 illustrates the effect of this extrapolation beyond the plateau value of $X_{\mathrm{p}} \simeq 0.7$. For other deformation and annealing conditions,

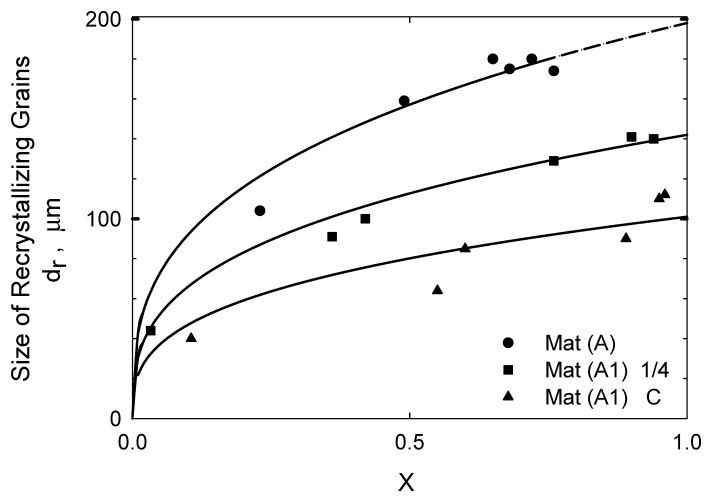

Fig. 15. Dependence of recrystallizing grain size on fraction recrystallized in $\operatorname{Mat}(\mathrm{A})\left(d_{0}=850 \mu \mathrm{m}, 16 \% \gamma\right.$, rolled to a strain of 0.82 at $1100^{\circ} \mathrm{C}$ and annealed at $\left.1100^{\circ} \mathrm{C}\right)$ and in Mat(A1), $\left(d_{0}-235 \mu \mathrm{m}, 0 \% \gamma\right.$ at $1 / 4$ thickness and $5 \% \gamma$ at the centre of slabs rolled to a strain of 0.82 at $900^{\circ} \mathrm{C}$ and annealed at $900^{\circ} \mathrm{C}$ ).

Table 1. Optimised values of constants in Eq. (6).

\begin{tabular}{|l|l|l|l|}
\hline$\% \boldsymbol{Y}$ & $\boldsymbol{a} \boldsymbol{\mu \boldsymbol { m } ^ { - 1 }}$ & $\boldsymbol{b} \boldsymbol{\mu \boldsymbol { m } ^ { - 2 }}$ & $\boldsymbol{c} \boldsymbol{\mu \boldsymbol { m } ^ { - 3 }}$ \\
\hline 0 & $2.4 \times 10^{-3}$ & $6.9 \times 10^{-6}$ & 0 \\
\hline 16 & 0 & $6.3 \times 10^{-5}$ & $5.0 \times 10^{-8}$ \\
\hline
\end{tabular}

the relevant values of $X_{\mathrm{p}}$ are shown in Figs. 6 and 9. The nucleation density per unit volume is then given by ${ }^{12)}$

$$
N_{\mathrm{v}}=A\left(d_{\mathrm{rex}}^{*}\right)^{-3}
$$

where $A$ is a geometrical constant, which depends on the grain size distribution.

When nucleation takes place preferentially at grain boundaries, the overall nucleation density is described by Appendix Eq. (A1). For the present deformation conditions of rolling to a strain of 0.82 at $1100^{\circ} \mathrm{C}$, the subgrain size, the probability terms and the geometrical terms are all expected to be constant. It is also considered that the first term in Eq. (A1) is small compared with the other terms and can be neglected, so that

$$
\left(\frac{1}{d_{\mathrm{rex}}{ }^{*}}\right)^{3}=\frac{a}{d_{0}^{2}}+\frac{b}{d_{0}}+c
$$

where $a, b$ and $c$ are constants. Optimisation of the values of each of these constants from the data for $0 \%$ and $16 \% \gamma$ in Fig. 11, with the constraint that they cannot be negative, leads to the results shown in Table 1. The lines drawn in Fig. 11 are obtained by substituting these values into Eq. (6) to obtain $d_{\mathrm{rex}}^{*}$ and applying Eq. (4) to obtain the values of $d_{\text {rex }}$. There are insufficient data to draw definitive conclusions about the operative mechanisms of nucleation of recrystallization from the values of the constants in Table 1. However, when there are no particles of austenite present, the fact that $c=0$ is consistent with the qualitative observation that all nucleation is associated with grain boundaries. When a volume of $16 \% \gamma$ particles is present during rolling, it is somewhat surprising that $a=0$, but this may reflect the fact that grain edges, i.e. triple points in micrographs, are completely occupied by austenite, so that mobile grain boundaries have been replaced by immobile $\alpha-\gamma$ boundaries. The value of $c=5.0 \times 10^{-8} \mu \mathrm{m}^{-3}$ indicates that 
about $15 \%$ of grains are nucleated at intragranular sites when $d_{0} \sim 200 \mu \mathrm{m}$, and that this fraction rises to about $40 \%$ when $d_{0}=850 \mu \mathrm{m}$, which is consistent with the qualitative observation of nucleation of recrystallized grains on intragranular particles of austenite, particularly in the coarser grained materials. There are very few data for intermediate volumes of austenite, but the qualitative observations ${ }^{1)}$ indicate that as the volume fraction of austenite decreases, both the number of particles per unit volume and the mean size of the particles decreases. Both these effects are expected to decrease the extent of particle stimulated nucleation, ${ }^{16)}$ so the influence of austenite may be expected to be a function of $(\% \gamma)^{n}$, where $n$ is greater than unity. In fact, to connect the values of $a, b$ and $c$ in Eq. (6) to optimise the agreement with the data for intermediate values of $\gamma \%$ and an initial grain size of $850 \mu \mathrm{m}$ in Fig. 10 requires a power of $n \simeq 3$, to give the line drawn in the figure. It should be emphasised that this value of the power arises from the specific relationships between number of particles per unit volume and the size of the austenite particles produced by the initial thermomechanical treatment of the present materials.

\subsection{Growth Rate}

The initial driving pressures $P_{\rho 0}$ for recrystallization are shown as a function of strain in Table 2. These values were calculated from the flow stress using Eq. (A6) by assuming $\alpha^{1} / \alpha=4$ and $C=20$, to obtain values of $\rho_{\mathrm{i}}$ for substitution into Eq. (A7), with the assumption that, over the experimental range of strain the value of $\mathrm{A}$ in Eq. (A8) is 0.05 radian.

When a plateau in recrystallization occurs in coarse grained material, recrystallizing grains nucleated at the boundaries of the coarsest grains in the distribution stop growing before lateral impingement has taken place. The situation can be represented schematically as shown in Fig. 16. If recrystallization were to continue in the absence of further nucleation, the existing recrystallizing grains would have to grow in a columnar manner to impinge at the centreline of the original grain. It can be seen that this requires the creation of new grain boundary area of energy, $\gamma$, per unit area.

From the geometry of the columnar grains, the length of boundary on a plane perpendicular to the growth direction is $\pi / 2 d_{\mathrm{r}}{ }^{17)}$ giving a retarding pressure

$$
P_{\mathrm{gb}}=\frac{\pi}{2} \frac{\gamma}{d_{\mathrm{r}}}
$$

This equation can only be valid when $d_{\mathrm{r}}<d_{0}$, otherwise some original grain boundaries would still be consumed as recrystallization proceeds. Substituting $\gamma=0.6 \mathrm{~J} / \mathrm{m}^{2}{ }^{16)}$ and the experimental values of $d_{\mathrm{r}}$ for the conditions under which growth rate was measured, leads to the values of $P_{\mathrm{gb}}$ shown in Table 2 . These values of $P_{\mathrm{gb}}$ are only 1 to $2 \%$ of the initial driving pressure. However, recovery is very rapid in ferrite at the high experimental annealing temperatures and the driving pressure falls rapidly.

The effect of recovery on reducing the driving pressure was calculated from Eqs. A(12) and A(13) by substituting a reasonable value of $C_{1}$ to obtain the results shown in Fig. 17. If the boundary mobility, $M$ in Eq. (A11) is constant, then for the single phase ferrite the lines in Fig. 17 should
Table 2. Calculated values of driving pressure and retarding pressure for recrystallization after deformation at $900^{\circ} \mathrm{C}$.

\begin{tabular}{|l|l|l|l|}
\hline Strain & $Y^{\%}$ & $\boldsymbol{P}_{\rho o}, P a$ & $\boldsymbol{P}_{g b}, P a$ \\
\hline 0.25 & 0 & $3.2 \times 10^{5}$ & - \\
\hline 0.41 & 0 & $3.8 \times 10^{5}$ & $4.6 \times 10^{3}$ \\
\hline 0.52 & 0 & $4.0 \times 10^{5}$ & $6.4 \times 10^{3}$ \\
\hline 0.82 & 5 & $4.5 \times 10^{5}$ & $8.4 \times 10^{3}$ \\
\hline
\end{tabular}

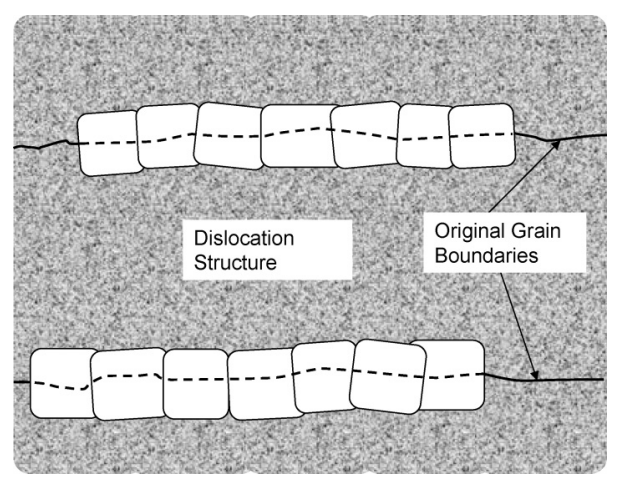

Fig. 16. Schematic diagram of recrystallizing grains growing into a coarse deformed grain.

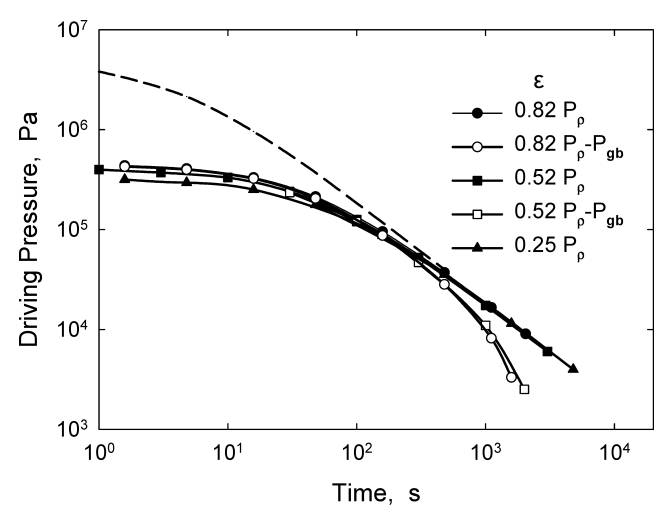

Fig. 17. Change in driving pressure for growth of recrystallizing regions calculated for homogenous dislocation density as a function of time of annealing at $900^{\circ} \mathrm{C}$ after rolling at $900^{\circ} \mathrm{C}$. The chain line indicates the effect of heterogeneity in dislocation structure.

be directly comparable with the experimental growth rates in Fig. 14. It can be seen that at longer annealing times the line in Fig. 17 for $P_{\rho}$ gives a power law of $t^{-1}$. This is also true for a strain of 0.25 (when $P_{\mathrm{gb}}=0$ ), as observed experimentally, whereas after higher strains, (when $P_{\mathrm{gb}}$ is real) the lines fall below the power law at long times, again as indicated by the experimental results for $G$. This predicted fall in net driving pressure to zero is consistent with the observation of plateaux in the recrystallization curves for some experimental conditions. This is discussed in detail elsewhere, ${ }^{9)}$ but the effects of initial grain size, Fig. 9, and the presence of austenite particles during rolling, Fig. 6, are considered to arise directly from their effects on the density of nucleation sites, and therefore on the rate of recrystallization relative to recovery.

At annealing times of more than about $100 \mathrm{~s}$, Fig. 17 shows the convergence of the driving pressure to a single line, as observed experimentally for $G$, Fig. 14. At shorter times, the lines deviate strongly from the power law. As dis- 
cussed by Furu et al. ${ }^{2)}$ for aluminium alloys, heterogeneity of the initial dislocation structure, because of local strain concentrations and lattice curvatures has a major effect on growth rate during recrystallization, because growth occurs initially in the regions of high driving pressure. If it is assumed that in local regions the driving pressure can be an order of magnitude higher than the mean value of $P_{\rho 0}$, the chain line in Fig. 17 is obtained. This approximates closely to a power law down to annealing times of the order of $10 \mathrm{~s}$, as found for the experimental growth rates, so it is concluded that heterogeneity of the initial dislocation structure plays a key role in the early stages of recrystallization. It is also possible that the boundary mobility, $M$, decreases with time, which would contribute to the reduction in $G$ and reduce the heterogeneity in driving pressure required for agreement with the experimental observations in Fig. 14. As discussed by Furu et al., ${ }^{2)}$ the experimental growth rates can still be fitted by an equation of the form

$$
G=G_{0}\left(1+\frac{t}{\tau_{1}}\right)^{-b}
$$

where the constant $b=1$ for the present results, but $\tau_{1}$ is less than expected for a homogeneous dislocation distribution. In analysing the experimental data, the effect of inhomogeneous deformation is allowed for by using an empirical constant $C_{2}$ in Eq. (8) so that from Eq. (A16)

$$
\frac{1}{\tau_{1}}=C_{2} \frac{b}{T} \cdot c_{j} \frac{D_{\mathrm{s}}}{M} \cdot G_{0}=C_{2} \frac{b}{T} c_{j} D_{\mathrm{s}} P_{\rho 0}
$$

For a given value of $G_{0}, \tau_{1}$ thus depends on the relative rate of recovery, characterised by $c_{j} D_{\mathrm{s}}$, and the mobility of migrating boundaries, characterised by $M$.

In the two phase materials the presence of austenite particles could provide a Zener drag on the migrating boundaries. Substituting reasonable values in Eq. (A9) leads to a value of $P_{\mathrm{z}} \leq 10 \mathrm{kPa}$ if the particles were randomly distributed. However, it is clear from Fig. 1 that the austenite is located preferentially at the grain boundaries and is frequently associated with nucleation of new grains. In the early stages of recrystallization, $P_{\mathrm{z}}$ may well be several times higher than the estimate, but $P_{\mathrm{z}} \ll P_{\rho}$. As recrystallization proceeds, the migrating boundaries encounter fewer and fewer particles so $P_{\mathrm{z}}$ decreases to well below the estimate and is therefore considered to remain negligible compared with $P_{\rho}$. From Fig. 14, it is seen that at all annealing times the growth rate with an initial $5 \% \gamma$ present is consistently a factor of about 2.5 less than in the single phase steel. This factor is clearly far too large to arise from any Zener drag effects, and Fig. 17 also indicates that a difference in driving pressure is unlikely to change the growth rate by a constant factor. It is therefore concluded that the slower growth arises from a reduced boundary mobility or higher recovery rate associated with the different levels of carbon in solution in alloys with austenite present, which is estimated to be $\sim 0.02 \% \mathrm{C}$ at $900^{\circ} \mathrm{C},{ }^{1)}$ compared with $\ll$ $0.02 \% \mathrm{C}$ in the decarburized single phase alloys.

\subsection{Overall Kinetics}

The migrating boundary area, $S_{\mathrm{v}}^{\mathrm{mig}}$, is expected to be related to $d_{\mathrm{r}}$ as ${ }^{12)}$

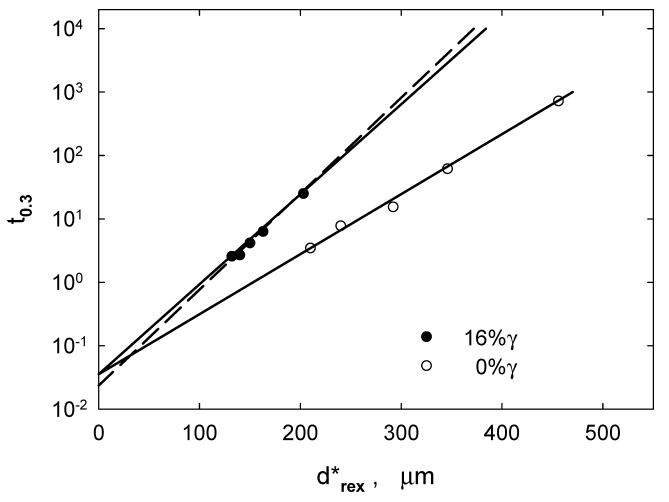

Fig. 18. Relationship between the time for 0.3 fraction of recrystallization and the grain size after complete recrystallization for material of different initial grain sizes and 0 or $16 \%$ austenite present during rolling to a strain of 0.82 at $1100^{\circ} \mathrm{C}$ and annealing at $1100^{\circ} \mathrm{C}$.

$$
S_{\mathrm{v}}^{\mathrm{mig}}=\frac{K_{\mathrm{v}}(X)(1-X)}{d_{\mathrm{r}}}
$$

where $K_{\mathrm{v}}$ is a geometrical constant $=2$ for equiaxed grains and remaining unrecrystallized volumes, but may increase with $X$ when the residual unrecrystallized volumes become increasingly elongated. From this relationship, Eq. (3) for site saturation and Eq. (8), the Cahn-Hagel equation ${ }^{1)}$ may be rewritten as

$$
d X \cdot \frac{d_{\mathrm{rex}}^{*}}{K_{\mathrm{v}} X^{2 / 3}(1-X)}=G_{0}\left(1+\frac{t}{\tau_{1}}\right)^{-1} d t \ldots \ldots . .
$$

Integration up to $t_{0.3}$, when $X=0.3$, gives

$$
0.6 d_{\text {rex }} * \simeq G_{0} \tau_{1} \cdot \ln \left(1+\frac{t_{0.3}}{\tau_{1}}\right)
$$

where the constant of 0.6 is obtained by numerical integration of the left hand side of Eq. (11) assuming $K_{\mathrm{v}} \sim 3$.

If $\tau_{1} \ll t_{0.3}$, then Eq. (12) becomes

$$
\log t_{0.3}=\frac{0.6 d_{\text {rex }}^{*}}{2.3 G_{0} \tau_{1}}+\log \tau_{1}
$$

Plotting the present data according to Eq. (13) for the values of $d_{\mathrm{rex}}^{*}$ obtained at $1100^{\circ} \mathrm{C}$ in materials of different initial grain size and austenite content, gives the results shown in Fig. 18. It can be seen that the data fit the relationship satisfactorily.

Substitution from Eq. (9) into Eq. (13), at $1100^{\circ} \mathrm{C}$ leads to

$$
\log t_{0.3}=C_{4} \cdot \frac{b}{T} c_{j} \frac{D_{\mathrm{s}}}{M} \cdot d_{\text {rex }} *-\log C_{5} \cdot \frac{b}{T} c_{j} D_{\mathrm{s}} P_{\rho 0}
$$

where $C_{4}$ and $C_{5}$ are constants.

The difference in slope of the lines in Fig. 18 by a factor of 1.5 indicates that $c_{j} D_{\mathrm{s}} / M$ is increased when austenite is present. Comparison with the results of growth measurements at $900^{\circ} \mathrm{C}$, Fig. 14, which indicate an increase in $c_{j} D_{\mathrm{s}} / M$ by a factor of $\sim 2.5$, when austenite is present shows that this ratio is not sensitive to temperature. Furthermore, if it is assumed (from the values of steady state flow stress) that $P_{\rho 0}$ in ferrite is independent of the presence of austen- 
ite, then Eq. (14) indicates that a decrease in growth rate because of a reduced value of $M$ when austenite is present does not affect the intercept in Fig. 18 (as shown by the solid line), whereas an increase in recovery rate, $c_{j} D_{\mathrm{s}}$, because of an increase in $D_{\mathrm{s}}$ by increase in carbon in solution, should decrease the intercept (as shown by the dashed line). Either intercept value is clearly within experimental uncertainty and the cause of the reduced growth rate requires further systematic experimental study. Overall the present results indicate that decarburization during annealing has only second order effects on the kinetics of recrystallization compared with the enhancement of nucleation produced by the presence of austenite particles during deformation.

\section{Conclusions}

(1) Optical microscopy of etched 3\% silicon steel after hot deformation shows the presence of a dislocation subgrain structure, but it appears that only boundaries of misorientation greater than a critical value are revealed, so the apparent subgrain size is larger than expected from the results of transmission electron microscopy, by a ratio that decreases with increasing strain, indicating that the mean subgrain boundary misorientation increases with strain.

(2) Nucleation of recrystallization approximates to site saturation. In single phase ferrite the sites appear to be exclusively at grain edges and grain faces. When particles of austenite are present during rolling, the density of sites on grain faces is enhanced and some nucleation occurs at intragranular particles.

(3) Inhomogeneity of the dislocation structure after deformation, rapid static recovery, and possibly a reduction in grain boundary mobility with time lead to a fall in growth rate by up to three orders of magnitude during recrystallization, with a dependence on $t^{-1}$ over most of the time interval.

(4) The driving pressure for recrystallization falls by recovery (and as a result of the heterogeneous distribution of initial stored energy) to such low levels that a retarding pressure associated with the creation of new grain boundary area in coarse grained material leads to a further fall in growth rate to zero after some time, so that recrystallization stops at a plateau level before completion.

(5) For identical conditions of deformation and annealing, the presence of austenite slows growth of recrystallizing regions by about a factor of 2.5 at $900^{\circ} \mathrm{C}$ and 1.5 at $1100^{\circ} \mathrm{C}$. The austenite particles cannot exert sufficient Zener drag to account for these factors, and it is probable that recovery rate is accelerated compared with boundary migration rate. This could arise from the presence of higher carbon in solution in ferrite in equilibrium with austenite than in the single phase ferrite materials. This leads to only a second order effect on recrystallization kinetics when decarburization takes place during annealing.

(6) The nucleation density produced by site saturation is directly reflected by the final recrystallized grain size. By combining the recrystallized grain size and the decreasing growth rate during recrystallization to describe the overall recrystallization kinetics, characterised by the time for 0.3 fraction of recrystallization, the separate effects of the microstructural variables on nucleation and growth can be quantified.

\section{REFERENCES}

1) S. Akta, G. J. Richardson and C. M. Sellars: ISIJ Int., 45 (2005), 1666.

2) T. Furu, K. Marthinsen and E. Nes: Mater. Sci. Technol., 6 (1990), 1093.

3) E. Nes, H. E. Vatne, O. Daaland, T. Furu, R. Orsund and K. Marthinsen: Proc. 4th Int. Conf. on Aluminium Alloys (ICAA4), The Georgia Inst. Technol., Atlanta, GA, USA, (1994), 18.

4) T. Furu, H. R. Shercliff, C. M. Sellars and M. F. Ashby: Proc. 5th Int. Conf. on Aluminium Alloys (ICAA5) ed. by J. H. Driver et al., Grenoble, France, (1996), Materials Science Forum, Transtec Publications, Uetikon-Zuerich, Switzerland, 217-222, Part 1, (1996), 385.

5) D. Duly, G. J. Baxter, H. R. Shercliff, J. A. Whiteman, C. M. Sellars and M. F. Ashby: Acta Mater., 44 (1996), 2947.

6) E. Vatne, T. Furu, R. Orsund and E. Nes: Acta Mater., 44 (1996), 4463.

7) E. Nes: Prog. Mater. Sci., 41 (1998), 129.

8) G. J. Baxter, T. Furu, Q. Zhu, J. A. Whiteman and C. M. Sellars: Acta Mater., 47 (1999), 2367.

9) S. Akta, G. J. Richardson and C. M. Sellars: ISIJ Int., 45 (2005), 1686.

10) S. Akta, G. J. Richardson and C. M. Sellars: ISIJ Int., 45 (2005), 1696.

11) J. W. Cahn and W. Hagel: Decomposition of Austenite by Diffusional Processes, eds. by V. F. Zackay and H. I. Aaronson, Interscience Publ., New York, (1962), 131.

12) P. L. Orsetti-Rossi and C. M. Sellars: Acta Mater., 45 (1997), 137.

13) R. L. Higginson and C. M. Sellars: Worked Examples in Quantitative Metallography, Maney Publications, London, (2003), 45.

14) G. H. Akbari, C. M. Sellars and J. A. Whiteman: Mater. Sci. Technol., 16 (2000), 47.

15) J. L. Uvira and J. J. Jonas: Trans Met. Soc. AIME., 242 (1968), 1619.

16) F. J. Humphreys and M. Hatherley: Recrystallisation and Related Annealing Phenomena, Pergamon Press, New York, (1996).

17) E. E. Underwood: Quantitative Stereology, Addison-Wesley Publishing Co. Inc. Philippines, (1970).

18) C. M. Sellars: Proc Int Conf on Thermomechanical Processing in Theory, Modelling and Practice, (TMP) $)^{2}$, ed. by B. Hutchinson et al., The Swedish Soc. for Materials Technology, Stockholm, Sweden, (1997), 35.

19) Q. Zhu, H. R. Shercliff and C. M. Sellars: Proc. Int. Conf. on Thermomechanical Processing of Steels and Other Materials, (Thermec '97), Vol. 2, ed. by T. Chandra and T. Sakai, TMS, Warrendale, PA, (1997), 2039.

20) C. M. Sellars: Proc. Int. Conf. on Thermomechanical Processing of Steels and Other Materials, (Thermec '97), Vol. 1, ed. by T. Chandra, and T. Sakai, TMS, Warrendale, PA, (1997), 3.

\section{Appendix. Physical Basis for Analysis of Recrystal- lization Kinetics}

The relationships used in the analysis of the recrystallization of 3\% Si Steel are all ones that have been applied previously to recrystallization data on aluminium alloys after hot deformation. These relationships are based on quantitative analysis of the dislocation structures in the as-deformed state. ${ }^{2-8)}$

The nucleation density per unit volume, $N_{\mathrm{v}}$, arises from preferential nucleation at grain boundaries and can be related to the subgrain size, $\delta$, as ${ }^{18)}$

$$
N_{\mathrm{v}}=p_{1} \lambda_{1} P_{\mathrm{v}}+p_{2} \lambda_{2} \frac{L_{\mathrm{v}}}{\delta}+p_{3} \lambda_{3} \frac{S_{\mathrm{v}}}{\delta^{2}}+p_{4} \lambda_{4} \frac{p_{\theta}}{\delta^{3}} \ldots
$$

where $P_{\mathrm{v}}$ is the number of grain corners per unit volume where four grains meet (which are rarely seen in optical microstructure sections), $L_{\mathrm{v}}$ is the line length per unit volume where three grains meet ('triple points' in optical micro- 
graphs), and $S_{\mathrm{v}}$ is the surface area per unit volume between two grains ('grain boundaries' in optical micrographs). These parameters depend on the original grain size, $d_{0}$, as $P_{\mathrm{v}} \propto d_{0}^{-3} . L_{\mathrm{v}} \propto d_{0}^{-2}$ and $S_{\mathrm{v}} \propto d_{0}^{-1}$ and the probability $p_{\theta}$ depends on finding a mobile boundary inside an original grain, e.g., a microband boundary of $\theta \geq 10^{\circ}$. The constants $\lambda_{1}$ to $\lambda_{4}$ depend on the geometry of the original grains with $\lambda_{2}$ and $\lambda_{3}$ (as well as $p_{\theta}$ ) being functions of strain, which depend on whether the deformation is axisymmetric or plane strain. ${ }^{17)}$ For plane strain rolling the value of $S_{\mathrm{v}}$ at any equivalent strain $\varepsilon$ is related to the original grain size as ${ }^{13)}$

$$
S_{\mathrm{v}}=\frac{1}{d_{0}}[0.429 \exp (-\varepsilon / 1.155)+\exp (\varepsilon / 1.55)+0.571]
$$

An equivalent relationship for $L_{\mathrm{v}}$ can be derived from the stereological equations ${ }^{17)}$ for plane strain rolling as

$$
\begin{aligned}
L_{\mathrm{v}} & =\frac{1}{d_{0}^{2}}[0.757 \exp (-\varepsilon / 1.155) \\
& +1.513 \exp (\varepsilon / 1.155)+0.757]
\end{aligned}
$$

The probabilities $p_{1}$ to $p_{4}$, determine the frequency with which sufficiently large differences in subgrain size exist across the area of the migrating boundary to create a viable nucleus.

The equivalent tensile flow stress at any strain is related to the subgrain size and to the density of dislocations inside the subgrains, $\rho_{\mathrm{i}}$, as ${ }^{19)}$

$$
\sigma=\sigma_{0}+\alpha \bar{M} \mu b \rho_{i}^{1 / 2}+\alpha^{1} \bar{M} \mu b \delta^{-1}
$$

where $\sigma_{\mathrm{o}}$ is a friction stress, $\alpha$ and $\alpha^{1}$ are constants, $\bar{M}$ is the Taylor factor, $\mu$ is the shear modulus and $b$ is the Burgers vector. Under steady state conditions the subgrain size and the dislocation density are related as

$$
\delta=C \rho_{i}^{-1 / 2}
$$

where $C$ is a constant of value in the range 10 to 30 for a number of metals under hot working conditions. Substituting Eq. (A5) into Eq. (A4) leads to the relationship

$$
\sigma=\sigma_{0}+\alpha \bar{M} \mu b \rho_{\mathrm{i}}^{1 / 2}\left(1+\frac{\alpha^{1}}{\alpha} \cdot \frac{1}{C}\right)
$$

At the end of deformation, the stored energy per unit volume provides the driving pressure, for recrystallization and is also related to the dislocation density and subgrain size as $^{20)}$

$$
P_{\rho 0}=\frac{\mu b^{2}}{10}\left[\rho_{\mathrm{i}}\left(1-\ln 10 b \rho_{\mathrm{i}}^{1 / 2}\right)+\frac{2 \theta}{b \delta}\left(1-\ln \frac{\theta}{\theta_{\mathrm{c}}}\right)\right]
$$

where $\theta$ is the angle of misorientation across the subgrain boundaries and $\theta_{\mathrm{c}}$ is a critical misorientation $\simeq 0.25$ radian. The value of $\theta$ increases with strain as

$$
\theta=A \varepsilon
$$

where $A$ is a constant over the range of strains $\leq 1$ of interest in the present work, but may fall to zero at higher strains. ${ }^{5,7,14)}$ Because a steady state flow stress is attained at strains of $\sim 0.2-0.4$ in $3 \%$ Si steel, ${ }^{1)} \rho_{\mathrm{i}}$ and $\delta$ become constant, but $\theta$ still increases so that stored energy continues to increase with strain.

In the presence of second phase particles (e.g. austenite, which is stronger than ferrite), migration is opposed by Zener drag ${ }^{16)}$

$$
P_{\mathrm{z}}=\frac{3 F_{\mathrm{v}} \gamma_{\mathrm{p}}}{2 r}
$$

where $F_{\mathrm{v}}$ is the volume fraction of second phase, $\gamma_{\mathrm{p}}$ is interphase boundary energy per unit area and $r$ is the radius of the particles, which are assumed to be spherical.

As discussed earlier from the present observations, when recrystallized grains consume the original grain boundaries at relatively low fractions of recrystallization, there is an increase in grain boundary area as recrystallisation proceeds and at relatively high fractions of recrystallization this retards boundary migration with a pressure

$$
P_{\mathrm{gb}} \simeq \frac{\pi}{2} \frac{\gamma}{d_{\mathrm{r}}}
$$

where $\gamma$ is the grain boundary energy per unit area and $d_{\mathrm{r}}$ is the linear intercept grain size of the recrystallizing grains.

The growth rate of recrystallizing colonies, $G$, (i.e. the migration rate of boundaries separating recrystallized grains from unrecrystallized grains) is then ${ }^{16)}$

$$
G=M\left(P_{\rho}-P_{\mathrm{z}}-P_{\mathrm{gb}}\right)
$$

where $M$ is the mobility of the migrating boundary.

In ferritic 3\% Si steel, static recovery is very rapid, so the dislocation density and hence $P_{\rho}$ in the unrecrystallized grains decreases with increasing annealing time. The recovery rates of subgrain boundaries and of internal dislocations differ, and heterogeneity of the as-deformed structures mean that recovery is a complex process in practice, but if it is considered to be characterised by the change in an effective dislocation density, $\rho$, then the rate of climb controlled recovery can be described as ${ }^{16)}$

$$
\frac{1}{\rho}=\frac{1}{\rho_{0}}+C_{1} t
$$

where $\rho_{\mathrm{o}}$ is the initial effective dislocation density calculated from the stored energ

$$
\rho_{0}=\frac{2 P_{\rho 0}}{\mu b^{2}}
$$

and $C_{1}$ is a constant

$$
C_{1}=\frac{2 c_{j} D_{s} \mu b^{3}}{k T}
$$

where $c_{j}$ is the concentration of jogs in the dislocations, $D_{\mathrm{s}}$ is the self diffusion coefficient, $k$ is Boltzmann's constant and $T$ is absolute temperature.

Rearranging Eq. (A12) leads to

$$
\rho=\rho_{\mathrm{o}}\left(1+C_{1} \rho_{\mathrm{o}} t\right)^{-1}
$$

Substituting from Eqs. (A13) and (A11) then leads to

$$
G=G_{0}\left(1+\frac{4 c_{j} D_{\mathrm{s}} b G_{0}}{M k T} \cdot t\right)^{-1}
$$

when $P_{\mathrm{gb}} \ll P_{\rho}$, which is applicable for short annealing times. 